\title{
Parathyroid Gland Disorder
}

National Cancer Institute

\section{Source}

National Cancer Institute. Parathyroid Gland Disorder. NCI Thesaurus. Code C26844.

A non-neoplastic or neoplastic disorder that affects the parathyroid glands.

Representative examples include hyperparathyroidism, hypoparathyroidism, adenoma, and carcinoma. 